\title{
CHARACTERIZATION AND COMPARISON OF SERRATIA MARCESCENS ISOLATED FROM EDIBLE CACTUS AND FROM SILKWORM FOR VIRULENCE POTENTIAL AND CHITOSAN SUSCEPTIBILITY
}

\author{
Bin $\mathrm{Li}^{1^{*}}$, Rongrong $\mathrm{Yu}^{2}$, Baoping Liu ${ }^{1}$, Qiaomei Tang ${ }^{1}$, Guoqing Zhang ${ }^{1}$, Yanli Wang ${ }^{3}$, Guanlin Xie ${ }^{1^{*}}$, Guochang Sun $^{3^{*}}$ \\ ${ }^{1}$ State Key Laboratory of Rice Biology, Key Laboratory of Molecular Biology of Crop Pathogens and Insects, Ministry of \\ Agriculture, Institute of Biotechnology, Zhejiang University, Hangzhou 310029, China; ${ }^{2}$ Zhejiang University of Technology, \\ Hangzhou 310032, China; ${ }^{3}$ State Key Laboratory Breeding Base for Zhejiang Sustainable Plant Pest and Disease Control, \\ Zhejiang Academy of Agricultural Sciences, Hangzhou 310021, China.
}

Submitted: March 17, 2010; Returned to authors for corrections: May 11, 2010; Approved: June 21, 2010.

\begin{abstract}
Representative strains of Serratia marcescens from an edible cactus plant and silkworms were characterized and a comparison based on their cellular fatty acid composition, 16S rRNA and groE gene sequence analysis as well as silkworm virulence and chitosan susceptibility was carried out. Results from this study indicate that there are no significant differences between the phenotypic and molecular characterization, virulence and chitosan susceptibility of the S. marcescens strains from the cactus plant and silkworms. Silkworms inoculated with S. marcescens from either plant or silkworm resulted in nearly $100 \%$ mortality. Chitosan solution exhibited strong antibacterial activity against $S$. marcescens. This activity increased with the increase of chitosan concentration and incubation time regardless of the strain source. Also, the results indicate that the plant associated $S$. marcescens maybe plays a possible role in the contamination of humans and animals, in particular silkworms, while chitosan showed a potential to control the contamination caused by $S$. marcescens.
\end{abstract}

Key words: Serratia marcescens, Cactus, Silkworm, Characterization, Virulence, Chitosan susceptibility

\section{INTRODUCTION}

Various plant-associated roles have been put forward for Serratia marcescens, including that of a plant pathogenic bacterium (19); an herbicide degradation bacterium (24); a plant growth promoting rhizobacterium (23); an innocuous colonizer or endophyte of plants (25); and even a biocontrol agent $(2,20)$. However, the enteric bacterium $S$. marcescens is also an opportunistic human and insect, in particular silkworm, pathogen $(5,7,9,15)$. Therefore, it is necessary to examine the differences between $S$. marcescens strains from plants and that from humans or animals, in particular silkworms.
Silkworms have been used as model animals for studying bacterial pathogenicity in humans (10), which made it possible for us to evaluate the virulence potential of plant associated $S$. marcescens in human or animal hosts. In addition, the abilities of S. marcescens to cause animal and human infections and survive in the environment have been partially attributed to its high natural resistance to antimicrobials and cleaning agents (8). Interestingly, chitosan is been well known for its broad antimicrobial activity $(3,11)$ and has shown a potential to control bacterial septicemic disease of silkworms caused by $S$. marcescens (14). Therefore, the bactericidal activity of chitosan against plant associated $S$. marcescens was examined 
in this work.

The aim of this study is to examine and compare phenotypic and molecular characterization as well as the virulence potential and chitosan susceptibility between the $S$. marcescens strains from an edible cactus and from silkworms.

\section{MATERIALS AND METHODS}

\section{Strains of $S$. marcescens}

Two representative strains of $S$. marcescens were used in this study; one from a plant and the other from an animal. Strain ZJ-C0701 of S. marcescens was isolated from the healthy tissue of edible cactus plants (Opuntia Milpa Alta) grown in Zhejiang province of China. Strain ZJ-S0801 of $S$. marcescens was kindly provided by the College of Animal Science, Zhejiang University, which was isolated from diseased silkworms.

\section{Phenotypic characterization}

Classical bacteriological tests were conducted as described by Schaad et al. (22). The bacterial strains were then grown for $24 \mathrm{~h}$ at $28{ }^{\circ} \mathrm{C}$ on TSBA (13) for analyses of fatty acid methyl ester (FAME; MIDI, Inc., Newark, DE) and substrate utilization (BIOLOG, Inc., Hayward, CA) profiles, which were performed following manufacturers' instructions (13). The BIOLOG tests were carried out using substrate plates designed for gram-negative bacteria. FAME testing was repeated a total of three times, and BIOLOG twice.

\section{Molecular characterization}

The 16S rRNA and groE gene of the bacterial strains were amplified and sequenced as described by Li et al. (12) and Harada and Ishikawa (6), respectively. Phylogenetic analysis was performed after including the consensus sequence in an alignment of small ribosomal subunit sequences collected from the international nucleotide sequence library GenBank. Nucleotides of the 16S rRNA and groE gene were aligned using CLUSTAL W. Phylogenetic and molecular evolutionary analyses were conducted using the genetic distance-based neighbor-joining algorithms within MEGA version 4.0 (http://www.megasoftware.net/). Bootstrap analysis for 1000 replicates was performed to estimate the confidence of tree topology.

\section{Virulence potential against silkworm}

Cultivation of bacteria: The bacterial strains were cultured for $48 \mathrm{~h}$ on nutrient agar medium at $28{ }^{\circ} \mathrm{C}$. After incubation, each bacterial suspension was prepared in sterilized water, and the initial concentration of bacteria was adjusted to approximately $10^{8}$ colony forming units $(\mathrm{CFU}) / \mathrm{ml}$. All bacterial strains involved in this study were deposited in the culture collection of the Institute of Biotechnology, Zhejiang University, China.

Rearing of silkworms: Hybrid strain larvae of silkworm (commercial name: Qingsong Haoyue) were reared at $25^{\circ} \mathrm{C}$ in this study. Fresh mulberry leaves (average size: $10 \mathrm{~cm} \times 20$ $\mathrm{cm}$ ) were obtained from a local mulberry farm (Hangzhou, China). Silkworm larvae were fed sufficient fresh mulberry leaves until the fifth instar and then were used for in vivo experiments.

The pathogenicity to silkworm: The virulence potential of the $S$. marcescens strains from both plant and silkworms were examined by inoculating them in silkworms, which were used as model animals for studying bacterial pathogenicity. The healthy larvae of uniform size and age were inoculated by pricking them at the third abdominal segment with sterile needles that had been dipped into $1.0 \mathrm{ml}$ of bacterial suspension $\left(10^{7} \mathrm{CFU} / \mathrm{ml}\right)$. The experiment was carried out in a randomized block design with three replicates of each treatment, with twenty larvae. Control larvae were inoculated with sterile water. Untreated healthy larvae were used as additional controls.

\section{Chitosan susceptibility}

Preparation of chitosan stock: Chitosan (degree of Ndeacetylation no less than $85 \%$, practical grade, from crab 
shells) was obtained from Sigma-Aldrich (St. Louis, MO, USA). Stock solution of chitosan $(5 \mathrm{mg} / \mathrm{ml})$ was prepared in $1 \%$ acetic acid with $\mathrm{pH}$ being adjusted to 6.0 with $\mathrm{NaOH}(11)$. After stirring (160 rpm) for $24 \mathrm{~h}$ at room temperature, the stock solution was autoclaved at $121{ }^{\circ} \mathrm{C}$ for $20 \mathrm{~min}$. Sterile deionized water of pH 6.0 was used as a control.

Surviving cells count: Bacterial suspensions were ten-fold serially diluted and $10 \mu \mathrm{l}$ samples were inoculated on nutrient agar medium in hexaplicate for each dilution and were incubated for $48 \mathrm{~h}$ at $28{ }^{\circ} \mathrm{C}$. After incubation, the surviving cells on the agar were counted based on the colony forming units and then the mean value of the cells at the lowest dilution was calculated. Each experiment was carried out in duplicate and was replicated twice.

Effect of chitosan concentration: Chitosan solutions of 5 $\mathrm{ml}$ in volume were prepared by adding chitosan stock to sterile deionized water to give a final chitosan concentration of 0.01 , 0.05 and $0.10 \mathrm{mg} / \mathrm{ml}$. Bacterial solution was added to $5 \mathrm{ml}$ of chitosan solution to give a final bacterial concentration of $10^{7}$ $\mathrm{CFU} / \mathrm{ml}$ and then the mixture was incubated at $28{ }^{\circ} \mathrm{C}$ in a rotary shaker (Hualida Company, Taicang, China) at $160 \mathrm{rpm}$. In the control treatment chitosan stock was replaced with sterile deionized water of $\mathrm{pH} 6.0$ in order to obtain the same pH. Two hours later, samples were collected from each cell suspension and bacterial counting was carried out as above.

Effect of incubation time: Chitosan solutions of $5 \mathrm{ml}$ in volume were prepared by adding $100 \mu \mathrm{l}$ chitosan stock to 4.90 $\mathrm{ml}$ sterile deionized water to give a final chitosan concentration of $0.10 \mathrm{mg} / \mathrm{ml}$. Bacterial strains were selected and inoculated into chitosan solution as described above. In the control treatment chitosan stock was replaced with sterile deionized water of $\mathrm{pH} 6.0$ in order to obtain the same $\mathrm{pH}$. Antibacterial activity of chitosan solution on the growth of $S$. marcescens was determined after $0.5,1.0,2.0$ and $4.0 \mathrm{~h}$ of incubation.

Statistical analysis: The software STATGRAPHICS Plus, version 4.0 (Copyright Manugistics Inc., Rockville, Md., USA) was used to perform the statistical analysis. Levels of significance $(\mathrm{P}<0.05)$ of main treatments and their interactions were calculated by analysis of variance after testing for normality and variance homogeneity.

\section{RESULTS AND DISCUSSION}

\section{Characterization of S. marcescens}

Results from this study indicated that there were no significant differences between the phenotypic and molecular characteristics of the $S$. marcescens strains from the cactus plant and silkworms. Both two strains formed red, smooth, convex, entire and round colonies on nutrient agar. Classical bacteriological tests showed that they were gram-negative, rod shaped and motile organisms. The fatty acid profiles of strain ZJ-C0701 were very similar to those of strain ZJ-S0801 (Table 1). Comparison of the fatty acid composition of strain $\mathrm{ZJ}$ C0701 and ZJ-S0801 with species from the bacteria database of the Microbial Identification System (Microbial ID, Inc.) gave a similarity index value of 0.56 and 0.58 with $S$. marcescens, respectively. However, it seems that the Biolog profiles are not suitable for the characterization of this bacterium due to the influence of pigment. The partial $16 \mathrm{~S}$ rRNA and groE gene sequence of strain ZJ-C0701 (EMBL accession No. FM883708, FM946180) and strain ZJ-S0801 (EMBL accession No. FM883709, FM946181) were determined and aligned to other known Enterobacteriaceae sequences deposited in GenBank (6). In the phylogenetic analysis, the two strains and $S$. marcescens were clustered within a group and were well separated from either the other Serratia species based on partial 16S gene sequences (Fig. 1) or the other genus of Enterobacteriaceae based on partial groE gene sequences (Fig. 2). 
Table 1. Analysis of cellular fatty acids of strain ZJ-C0701 of S. marcescens from edible cactus plant and comparison with strain ZJ-S0801 of S. marcescens from silkworm

\begin{tabular}{lcc}
\hline Fatty acid & \multicolumn{2}{c}{ Cellular fatty acids (\%) } \\
\cline { 2 - 3 } & ZJ-C0701 & ZJ-S0801 \\
\hline $10: 0$ & 0.23 & 0.25 \\
$10: 03 \mathrm{OH}$ & 3.01 & 2.89 \\
$12: 0$ & 1.12 & 1.38 \\
$12: 0 \mathrm{OH}$ & 0.40 & 0.51 \\
$12: 03 \mathrm{OH}$ & 1.51 & 1.35 \\
$14: 0$ & 4.86 & 5.16 \\
$14: 02 \mathrm{OH}$ & 3.80 & 2.10 \\
$14: 03 \mathrm{OH}$ & 7.05 & 8.12 \\
$16: 0$ & 30.80 & 28.55 \\
$16: 03 \mathrm{OH}$ & 0.18 & 0.22 \\
$16: 1 \mathrm{w} 7 \mathrm{c}$ & 11.46 & 12.20 \\
$17: 0$ & 1.31 & 1.19 \\
$17: 0 \mathrm{cyclo}$ & 15.26 & 14.71 \\
$18: 0$ & 0.39 & 0.26 \\
$18: 1 \mathrm{w} 7 \mathrm{c}$ & 15.12 & 16.58 \\
\hline
\end{tabular}

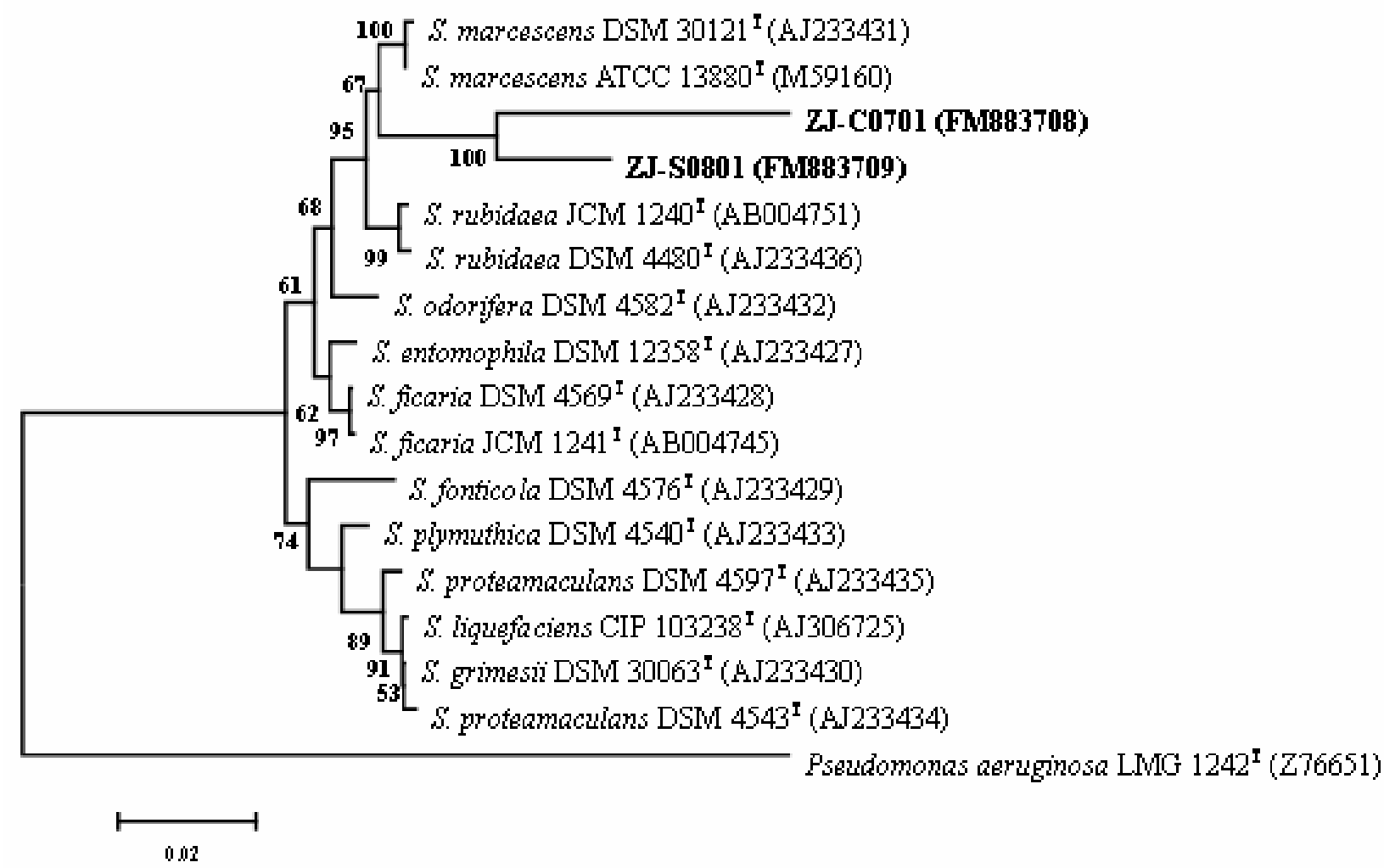

Figure 1. Phylogenetic tree derived from partial 16S rRNA gene sequence analysis on strain ZJ-C0701 and ZJ-S0801 as well as reference strains of each Serratia species. The tree was generated by the neighbor-joining method based on the two-parameter Kimura correction of evolutionary distances. Bootstrap analyses (1000 replicates) for node values from 50\% are indicated. Pseudomonas aeruginosa was used as the outgroup. 


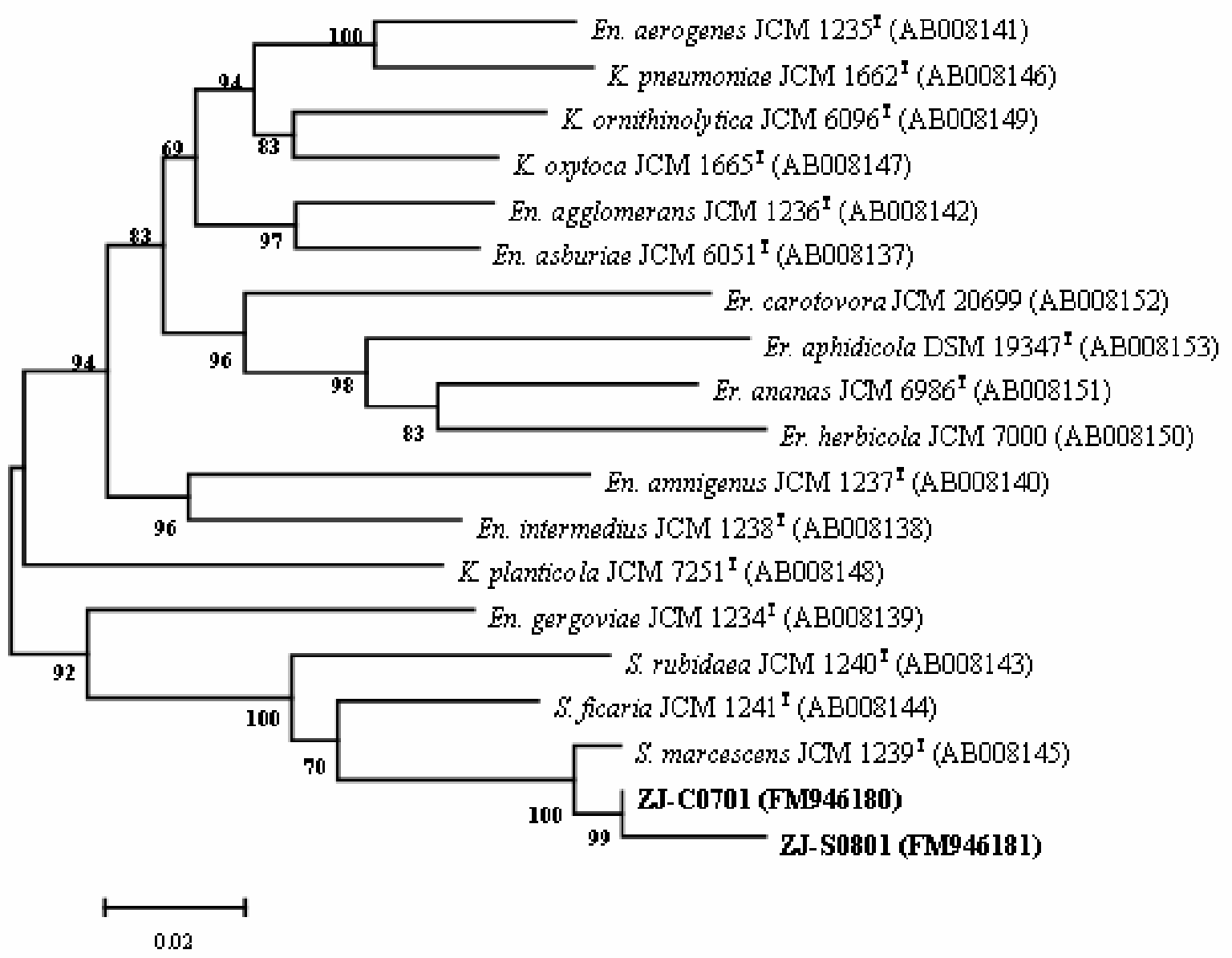

Figure 2. Phylogenetic tree derived from partial groE gene sequences analysis on strain ZJ-C0701 and ZJ-S0801 as well as reference strains of the genus Serratia (S.), Erwinia (Er.), Enterobacter (En.) and Klebsiella (K.). The tree was generated by the neighbor-joining method based on the two-parameter Kimura correction of evolutionary distances. Bootstrap analyses (1000 replicates) for node values from $50 \%$ are indicated.

\section{Comparison of virulence potential}

The silkworm larvae inoculated with strain ZJ-S0801 resulted in $73.3 \%, 86.7 \%$ and $93.3 \%$ mortality, while inoculation with strain $\mathrm{ZJ}-\mathrm{C} 0701$ resulted in $93.3 \%, 96.7 \%$ and $96.7 \%$ mortality after 24,48 and $72 \mathrm{~h}$ of rearing, respectively. In addition, the causal bacteria reisolated from inoculated silkworm larvae have morphology identical to those of the original inoculated culture of $S$. marcescens, which implied that there was no significant difference in virulence between the $S$. marcescens strains from the cactus plant and silkworms. The mortality of the larvae treated with sterile water and uninoculated control was $0 \%$ regardless of the rearing time.
Thus, these results suggest that the plant strain maybe play a possible role in the contamination of humans and animals.

In agreement with the results of this study, vegetable plants as a habitat for beneficial and/or human pathogenic bacteria have received considerable attention (1, 17, 18). Indeed, increasing numbers of foodborne illness outbreaks have been traced to the consumption of plant-derived foods. While a number of outbreaks caused by Escherichia coli O157:H7, Listeria monocytogenes and Salmonella enterica have been linked to the consumption of contaminated fruit and vegetable produce $(4,16,21)$. However, this is first report that plant associated $S$. marcescens maybe is a potential risk for humans 
and animal health.

\section{Comparison of chitosan susceptibility}

Chitosan solution at different concentrations showed effective antibacterial activity against $S$. marcescens strains isolated from both the cactus plant and silkworms. In addition, chitosan solutions up to $0.10 \mathrm{mg} / \mathrm{ml}$ showed stronger antibacterial activity against $S$. marcescens compared with the remainder treatment, which is consistent with the result of $\mathrm{Li}$ et al. (11), who found that the antibacterial activity of chitosan was influenced by its concentration in the solution. The surviving cell numbers of strain ZJ-C0701 in chitosan solution of $0.01 \mathrm{mg} / \mathrm{ml}$ decreased $1.74 \log _{10} \mathrm{CFU} / \mathrm{ml}$, while the surviving cell numbers in chitosan solution of $0.10 \mathrm{mg} / \mathrm{ml}$ decreased $2.24 \log _{10} \mathrm{CFU} / \mathrm{ml}$ compared to the control (Fig. 3). Similarly, the surviving cell numbers of strain ZJ-S0801 in chitosan solution of $0.01 \mathrm{mg} / \mathrm{ml}$ decreased $1.92 \log _{10} \mathrm{CFU} / \mathrm{ml}$, while the surviving cell numbers in chitosan solution of 0.10 $\mathrm{mg} / \mathrm{ml}$ decreased $2.61 \log _{10} \mathrm{CFU} / \mathrm{ml}$ compared to the control
(Fig. 4).

The antibacterial activity of chitosan against $S$. marcescens strains was affected by the incubation time. In the absence of chitosan, the surviving cell numbers of strain ZJ-C0701 in sterile deionized water decreased $0.18 \log _{10} \mathrm{CFU} / \mathrm{ml}$ after $0.5 \mathrm{~h}$ of incubation compared with the starting value of $7.53 \log _{10}$ $\mathrm{CFU} / \mathrm{ml}$. With the increase of incubation time, the surviving cell numbers remained stable (Table 2). In the presence of chitosan, the surviving cell numbers decreased significantly compared to the starting value. The antibacterial activity of the chitosan solution of $0.10 \mathrm{mg} / \mathrm{ml}$ increased with the incubation time through to $4.0 \mathrm{~h}$. After $0.5 \mathrm{~h}$ of incubation, the surviving cell numbers in the chitosan solution decreased $1.20 \log _{10}$ $\mathrm{CFU} / \mathrm{ml}$ compared to the starting value and after $4.0 \mathrm{~h}$ of incubation, the surviving cell numbers in the chitosan solution decreased $2.78 \log _{10} \mathrm{CFU} / \mathrm{ml}$ compared to the starting value (Table 2), which shows that a certain incubation time is required for the antibacterial activity of chitosan solution to take effect.

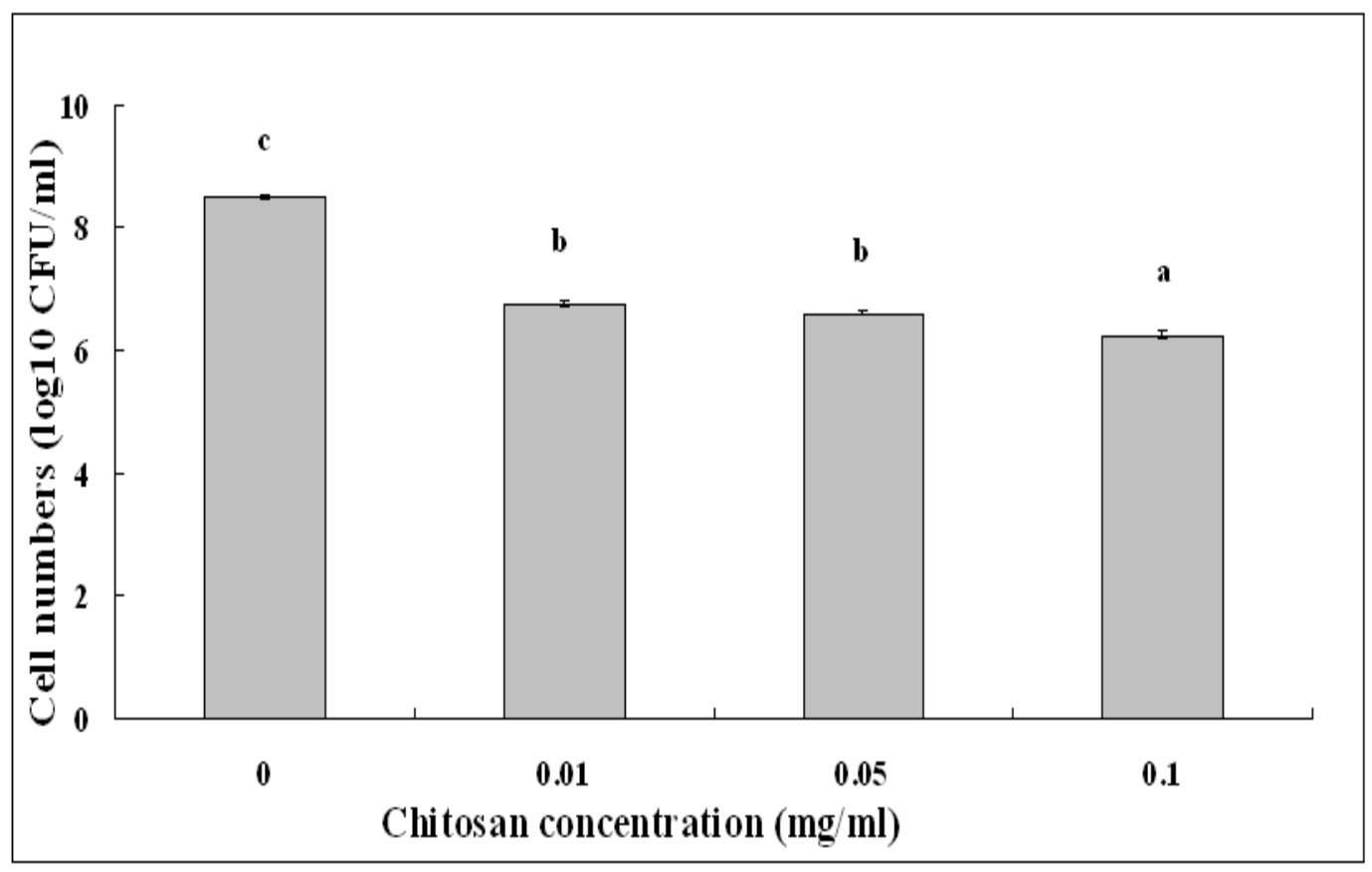

Figure 3. Effect of chitosan concentration on the antibacterial activity of strain ZJ-C0701 of S. marcescens. Columns with the same letters are not significantly different $(\mathrm{P}<0.05)$. Error bars represent the standard error of the mean $(n=6)$. Data are from a representative experiment repeated twice with similar results. 


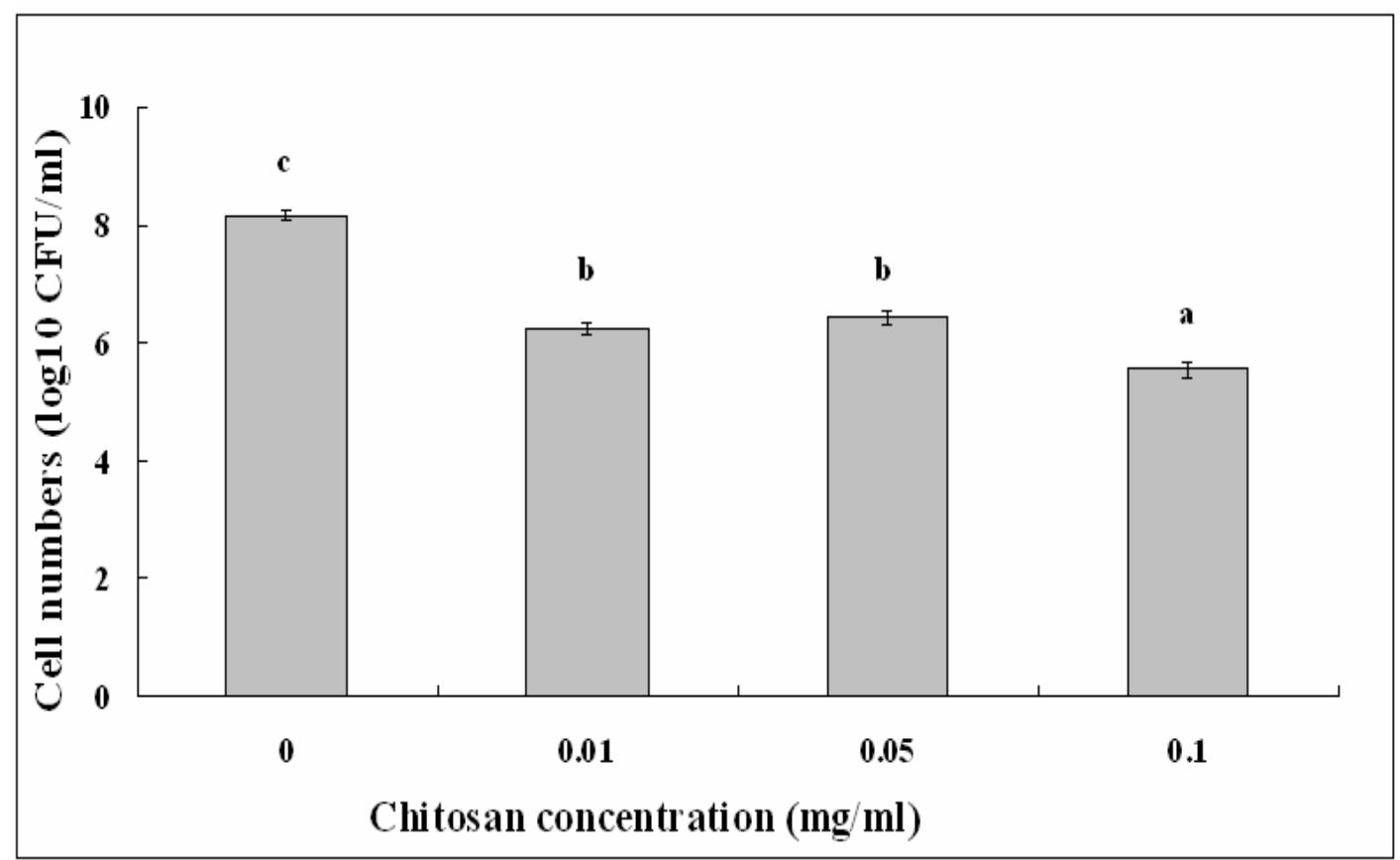

Figure 4. Effect of chitosan concentration on the antibacterial activity of strain ZJ-S0801 of S. marcescens. Columns with the same letters are not significantly different $(P<0.05)$. Error bars represent the standard error of the mean $(n=6)$. Data are from a representative experiment repeated twice with similar results.

Table 2. Effect of incubation time on the antibacterial activity of chitosan solution at $0.10 \mathrm{mg} / \mathrm{ml}$ against strain ZJ-C0701 of $S$. marcescens $^{a}$

\begin{tabular}{ccc}
\hline Incubation time (h) & \multicolumn{2}{c}{ Cell numbers $\left(\log _{\mathbf{1 0}} \mathbf{C F U} / \mathbf{m l}\right)$} \\
& Control & $7.53 \pm 0.15 \mathrm{~d}$ \\
0.0 & $7.53 \pm 0.15 \mathrm{a}$ & $6.33 \pm 0.10 \mathrm{c}$ \\
0.5 & $7.35 \pm 0.11 \mathrm{a}$ & $6.21 \pm 0.09 \mathrm{c}$ \\
1.0 & $7.20 \pm 0.13 \mathrm{a}$ & $5.78 \pm 0.10 \mathrm{~b}$ \\
2.0 & $7.22 \pm 0.10 \mathrm{a}$ & $4.75 \pm 0.09 \mathrm{a}$ \\
4.0 & $7.27 \pm 0.10 \mathrm{a}$ & ${ }^{a}$ Thesan \\
\hline
\end{tabular}

${ }^{a}$ The data were shown as means \pm standard error from a representative experiment repeated twice with similar results. All the means within a column followed by the same letter are not significantly different $(\mathrm{P}<0.05$, Fisher's LSD test). Each value represents the average of six replicates.

In agreement with the antibacterial effect of chitosan solution against strain $\mathrm{ZJ}-\mathrm{C} 0701$, the surviving cell numbers of strain ZJ-S0801 remained stable in the absence of chitosan (Table 3). In the presence of chitosan, the surviving cell numbers decreased significantly compared to the starting value. The antibacterial activity of the chitosan solution of 0.10 $\mathrm{mg} / \mathrm{ml}$ against strain ZJ-S0801 increased with the incubation time through to $4.0 \mathrm{~h}$. The surviving cell numbers in the chitosan solution decreased $1.36 \log _{10} \mathrm{CFU} / \mathrm{ml}$ after $0.5 \mathrm{~h}$ of incubation, and they decreased $2.40 \log _{10} \mathrm{CFU} / \mathrm{ml}$ after $4.0 \mathrm{~h}$ of incubation compared to the starting value (Table 3 ).

The results from this study indicate that there was no significant difference in chitosan susceptibility between the $S$. marcescens strains from the cactus plant and silkworms. In the last three decades there has been a steady increase in nosocomial $S$. marcescens infections that can be life- 
threatening to both animals and humans (7). As many $S$. marcescens strains are also resistant to multiple antibiotics (5, $7,15)$, it represents a growing problem for animal and public health. Considering the absence of any sort of remedial measures for $S$. marcescens infections, the present investigation may prove helpful. The antibacterial activity of chitosan may be enhanced by combination with radiation processing in the control of S. marcescens.

Table 3. Effect of incubation time on the antibacterial activity of chitosan solution at $0.10 \mathrm{mg} / \mathrm{ml}$ against strain ZJ-S0801 of $S$. marcescens $^{a}$

\begin{tabular}{ccc}
\hline Incubation time $(\mathbf{h})$ & \multicolumn{2}{c}{ Cell numbers $\left(\log _{\mathbf{1 0}} \mathbf{C F U} / \mathbf{m l}\right)$} \\
& Chitosan \\
\hline 0.0 & $7.69 \pm 0.17 \mathrm{a}$ & $7.69 \pm 0.17 \mathrm{~d}$ \\
0.5 & $7.37 \pm 0.17 \mathrm{a}$ & $6.33 \pm 0.12 \mathrm{c}$ \\
1.0 & $7.59 \pm 0.17 \mathrm{a}$ & $6.31 \pm 0.10 \mathrm{c}$ \\
2.0 & $7.53 \pm 0.11 \mathrm{a}$ & $5.97 \pm 0.09 \mathrm{~b}$ \\
4.0 & $7.53 \pm 0.13 \mathrm{a}$ & $5.29 \pm 0.10 \mathrm{a}$ \\
\hline${ }^{a}$ The data were shown as means \pm standard error from a representative experiment repeated twice with similar results. All the \\
means within a column followed by the same letter are not significantly different (P<0.05, Fisher's LSD test). Each value \\
represents the average of six replicates.
\end{tabular}

\section{CONCLUSION}

In summary, our results clearly demonstrated that there was no significant difference between the phenotypic and molecular characterization, virulence and chitosan susceptibility of the $S$. marcescens strains from the cactus plant and silkworms, which indicated that the plant strain maybe play a possible role in the contamination of human and animals alike. In addition, results from this study showed that a chitosan solution has a strong antibacterial activity against plant associated $S$. marcescens, which will be helpful in the control of contaminated fruit and vegetable produce.

\section{ACKNOWLEDGEMENTS}

This project was supported by Zhejiang Provincial Natural Science Foundation of China (Y3090150), the Fundamental Research Funds for the Central Universities (KYJD09022), National Natural Science Foundation of China (30600475) and the Agricultural Ministry of China (nyhyzx200803010).

\section{REFERENCES}

1. Caggia, C.; Randazzo, C.L.; Di Salvo, M.; Romeo, F.; Giudici, P. (2004).
Occurrence of Listeria monocytogenes in green table olives. J. Food Prot. 67, 2189-2194.

2. de Queiroz, B.P.V.; de Melo, I.S. (2006). Antagonism of Serratia marcescens towards Phytophthora parasitica and its effects in promoting the growth of citrus. Braz. J. Microbiol. 37, 448-450.

3. Fang, Y.; Lou, M.M.; Li, B.; Xie, G.L.; Wang, F.; Zhang, L.; Luo, Y.C. (2010). Characterization of Burkholderia cepacia complex from cystic fibrosis patients in China and their chitosan susceptibility. World J. Microb. Biot. 26, 443-450.

4. Gorski, L.; Palumbo, J.D.; Nguyen, K.D. (2004). Strain-specific differences in the attachment of Listeria monocytogenes to alfalfa sprouts. J. Food Prot. 67, 2488-2495.

5. Guimaraes, M.A.; Tibana, A.; Nunes, M.P.; dos Santos, K.R.N. (2000). Disinfectant and antibiotic activities: A comparative analysis in Brazilian hospital bacterial isolates. Braz. J. Microbio. 31, 193-199.

6. Harada, H.; Ishikawa, H. (1997). Phylogenetical relationship based on groE genes among phenotypically related Enterobacter, Pantoea, Klebsiella, Serratia and Erwinia species. J. Gen. Appl. Microbiol. 43, 355-361.

7. Hejazi, A.; Falkiner, F.R. (1997). Serratia marcescens. J. Med. Microbiol. 46, 903-912.

8. Iranshahi, M.; Shahverdi, A.R.; Mirjani, R.; Amin, G.; Shafiee, A. (2004). Umbelliprenin from Ferula persica roots inhibits the red pigment production in Serratia marcescens. Z. Naturforsch C. 59, 506-508.

9. Iwaya, A.; Nakagawa, S.; Iwakura, N.; Taneike, I.; Kurihara, M.; Kuwano, T.; Gondaira, F.; Endo, M.; Hatakeyama, K.; Yamamoto, T. (2005). Rapid and quantitative detection of blood Serratia marcescens by a real-time PCR assay: Its clinical application and evaluation in a mouse infection model. FEMS Microbiol. Lett. 248, 163-170. 
10. Kaito, C.; Akimitsu, N.; Watanab, H.; Sekimizu, K. (2002). Silkworm larvae as an animal model of bacterial infection pathogenic to humans. Microb. Pathog. 32, 183-190.

11. Li, B.; Wang, X.; Chen, R.X.; Huangfu, W.G.; Xie, G.L. (2008b). Antibacterial activity of chitosan solution against Xanthomonas pathogenic bacteria isolated from Euphorbia pulcherrima. Carbohyd. Polym. 72, 287-292.

12. Li, B.; Xie, G.L.; Zhang, J.Z.; Janssens, D.; Swings, J. (2006). Identification of the bacterial leaf spot pathogen of poinsettia in China. $J$. Phytopathol. 154, 711-715.

13. Li, B.; Xu, L.H.; Lou, M.M.; Li, F.; Zhang, Y.D.; Xie, G.L. (2008a). Isolation and characterization of antagonistic bacteria against bacterial leaf spot of Euphorbia pulcherrima. Lett. Appl. Microbiol. 46, 450-455.

14. Li, B.; Su, T.; Chen, X.L.; Liu, B.P.; Zhu, B.; Fang, Y.; Qiu, W.; Xie, G.L. (2009). Effect of chitosan solution on the bacterial septicemia disease of Bombyx mori (Lepidoptera: Bombycidae) caused by Serratia marcescens. Appl. Entomol. Zool. 45, 145-152.

15. Loureiro, M.M.; de Moraes, B.A.; Quadra, M.R.R.; Pinheiro, G.S.; Asensi, M.D. (2002). Study of multi-drug resistant microorganisms isolated from blood cultures of hospitalized newborns in Rio de Janeiro city, Brazil. Braz. J. Microbiol. 33, 73-78.

16. Milillo, S.R.; Badamo, J.M.; Boor, K.J.; Wiedmann, M. (2008). Growth and persistence of Listeria monocytogenes isolates on the plant model Arabidopsis thaliana. Food Microbiol. 25, 698-704.

17. Rahme, L.G.; Ausubel, F.M.; Cao, H.; Drenkard, E.; Goumnerov, B.C.; Lau, G.W.; Mahajan-Miklos, S.; Plotnikova, J.; Tan, M.W.; Tsongalis, J.; Walendziewicz, C.L.; Tompkins, R.G. (2000). Plants and animals share functionally common bacterial virulence factors. Proc. Natl. Acad. Sci. USA 97, 8815-8821.

18. Rahme, L.G.; Stevens, E.J.; Wolfort, S.F.; Shao, J.; Tompkins, R.G.; Ausubel, F.M. (1995). Common virulence factors for bacterial pathogenicity in plants and animals. Science 268, 1899-1902.

19. Rascoe, J.; Berg, M.; Melcher, U.; Mitchell, F.L.; Bruton, B.D.; Pair, S.D.; Fletcher, J. (2003). Identification, phylogenetic analysis, and biological characterization of Serratia marcescens strains causing cucurbit yellow vine disease. Phytopathology 93, 1233-1239.

20. Roberts, D.P.; McKenna, L.F.; Lakshman, D.K.; Meyer, S.L.F.; Kong, H.; de Souza, J.T.; Lydon, J.; Baker, C.J.; Buyer, J.S.; Chung, S. (2007). Suppression of damping-off of cucumber caused by Pythium ultimum with live cells and extracts of Serratia marcescens N4-5. Soil Biol. Biochem. 39, 2275-2288.

21. Samadpour, M.; Barbour, M.W.; Nguyen, T.; Cao, T.M.; Buck, F.; Depavia, G.A.; Mazengia, E.; Yang, P.; Alfi, D.; Lopes, M.; Stopforth, J.D. (2006). Incidence of enterohemorrhagic Escherichia coli, Escherichia coli $\mathrm{O} 157$, Salmonella, and Listeria monocytogenes in retail fresh ground beef, sprouts, and mushrooms. J. Food Prot. 69, 441-443.

22. Schaad, N.W.; Jones, J.B.; Chun, W. (2001). Laboratory guide for identification of plant pathogenic bacteria. 3rd Edition. American Phytopathological Society, St. Paul, Minn.

23. Selvakumar, G.; Mohan, M.; Kundu, S.; Gupta, A.D.; Joshi, P.; Nazim, S.; Gupta, H.S. (2008). Cold tolerance and plant growth promotion potential of Serratia marcescens strain SRM (MTCC 8708) isolated from flowers of summer squash (Cucurbita pepo). Lett. Appl. Microbiol. 46, $171-175$.

24. Silva, T.M.; Stets, M.I.; Mazzetto, A.M.; Andrade, F.D.; Pileggi, S.A.V.; Favero, P.R.; Cantu, M.D.; Carrilho, E.; Carneiro, P.I.B.; Pileggi, M. (2007). Degradation of 2,4-D herbicide by microorganisms isolated from Brazilian contaminated soil. Braz. J. Microbiol. 38, 522-525.

25. Tan, Z.; Hurek, T.; Gyaneshwar, P.; Ladha, J.K.; Reinhold-Hurek, B. (2001). Novel endophytes of rice form a taxonomically distinct subgroup of Serratia marcescens. Syst. Appl. Microbiol. 24, 245-251. 